lection were also made by Dr. Mantell, Dr. Macculloch, and Mr. Leonard Horner.

It will be recollected that the Society was originated in 1807 , at a time when mineralogy was a fashionable study, or at least when collections of minerals formed part of the "furniture" of the apartments of the Queen and many of the nobility. Collections of shells and of fossils were also fashionable, but they were valued only for their beauty or their rarity, and not for any knowledge of nature they afforded. For some time the young society seems to have followed fashion. Indeed, the value of fossil organic remains as giving a clue to the consecutive sequence and relative order of strata was then but just beginning to be understood. It was not till the end of 1799 that the first MS. table of the sequence from the Carboniferous beds upwards was constructed, and no map of the strata of England was published till I8I5. The earliest MS. catalogue of specimens belonging to the Society, begun in 1808 or 1809 , is labelled "General Catalogue of Minerals," and some of the early entries of organic fossils refer rather to the rock in which the fossil is imbedded; the presence of the fossil being but casually noticed, such as "limestone containing shells." These early collections of fossils illustrating the labours of the first geologists in using organic remains to trace the chronological sequence of beds, and to compile some chapters of the earth's history, have a profound interest, laying as they did the foundations of a science which has placed at rest many wild theories of the origin of the earth, and has, too, proved to be of such practical value. The first donation recorded is $\mathrm{Feb}$. 5 th, I 808, of specimens from St. Anthon's Colliery, Newcastleupon-Tyne, by the Right Hon. Sir J. Banks. It would occupy too much space to mention all the collections that the Society has preserved, but among the donors are the well-known names of Sir Henry de la. Beche, Sir Charles Lyell, Greenough, Warburton, and Sir Woodbine Parish. McEnery's collection that first brought Kent's Cavern into notice is there, and so is a splendid series of Daniel Sharpe's "Brachiopoda." The old red sandstone fishes presented by Lady Gordon Cumming are remarkable for their beauty as well as for the extent of the collection.

Many distinguished living geologists have private collections of their own ; for example, the Earl of Enniskillen, Sir Philip Egerton, Prof. Prestwich, Mr. Searles Wood, Dr. Bowerbank, \&c., which fully explains why their contributions are not so numerous as might be expected from the valuable work they have done. Prof。 Phillips, though so energetic a worker, is not largely represented in the museum, for firstly York, and afterwards Oxford, had stronger claims on him. The same remark applies somewhat to the claims of the Woodwardian Museum on Prof. Sedgwick. As illustrating the geology of England generally, the Jermyn Street Museum and the British Museum are more useful, but as a record of early geological work the museum of the Society is unique.

The rearrangement of the foreign collections has not yet been completed, though it is in progress. Suites of specimens are to be seen there from all parts of the known world from which it has been possible for travellers to send them. These foreign collections are, to some extent, the result of contributions by officers in Her Majesty's services. Central Africa is not represented, but there are several collections from both coasts. For the future it is intended to add to the British collection only those specimens that are sent in illustration of papers read to the Society, but foreign specimens will be received as before.

Among the treasures of the museum, besides the rocks and fossils, there are the original drawings of Agassiz's "Poissons Fossiles," presented by the Earl of Enniskillen, the first manuscript geological map of England (1799), and the first table of strata, by W. Smith (I799).

The previous changes in the locality of the museum have been as follows :-In No. 4, Garden Court, Temple, the first fixed habitation of the Society (June 1809), the collection was commenced. In June 1810 it was removed to 3, Lincoln's Inn Fields; in June 1816 to 20 , Bedford Street; in the autumn of 1828 , to Somerset House; at Somerset House it has remained till this last move to Burlington House.

\section{CONDENSED AIR TRAMWAYS}

FOR some weeks the North Paris Tramways Company has been trying on the line from Courbevoie to the Arc de l'Etoile a new system of locomotion, in which the motive power is compressed air. Some details of M. Mékarski's (the inventor) system are given in the Revue Scientifique. It is capable of considerable developments and of varied applications, since it has solved in a very satisfactory manner the double problem of the industrial production of air condensed to very high pressures, and of the storage of the air in reservoirs intended to discharge into a cylinder placed in any apparatus whatever, at any distance from the condensing pump.

The "Voiture Automatique" of M. Mékarski is characterised by the absence of an imperial and by a platform in front and another behind. This car carries the reservoirs of condensed air, the apparatus for distribution, and the cylinders. M. Mékarski places under the truck of the car the sheet-iron cylinders, which contain the condensed air ; on the front platform is placed the distributing apparatus which the engine-man works; the two cylinders are placed, as in certain locomotives, outside the framework, horizontally, and act directly, by means of a crank, on the front wheels of the car. No doubt this arrangement might be advantageously modified; but the important point is the possibility of manufacturing compressed air in sufficient quantities to be of use as a motive power.

The condensing apparatus used by M. Mékarski consists of two pump-barrels of cast-iron, placed vertically communicating respectively with two horizontal pumpbarrels, in which move two pistons worked by a steamengine. This is, in reality, a double condensing pump, the former bringing the air to the pressure of from ten to twelve atmospheres, and the second raising the pressure to twenty-five atmospheres. The pistons act upon a mass of water which compresses the air directly and absorbs by degrees the heat disengaged by compression. By an ingenious contrivance the supply of water is continually renewed, and the temperature thus kept down. But this arrangement does not absorb a sufficient amount of the heat disengaged, a difficulty which $M$. Mékarski has met as follows. The external air drawn into the pump raises a valve constantly covered by a layer of water of several centimetres; besides, a large cast-iron tube, constantly traversed by the air already condensed and the excess of water, communicates with the two vertical pump.barrels ; finally, the second pump is fitted with a tap by which the heated water escapes.

In M. Mékarski's automatic car the compressed air is stored, under the truck, in sheet-iron reservoirs or cylinders. The total capacity is about 2,000 litres; $I, 500$ litres serve as an orcuinary supply; 300 litres constituting a reserve ; the remaining 200 litres are intended to serve as a brake. The air is compressed in the cylinders to the pressure of twenty-five atmospheres. On the line from Courbevoie to the Arc de Triomphe, 7,500 metres going and returning, the resistance is unusually great. In one experiment the ordinary feeding cylinders contained I, 500 litres of twenty-five atmospheres at departure, and the pressure, on arrival, was not more than four and a quarter atmospheres. The expenditure had thus been about I,250 litres at twenty-five atmospheres for a run of 7,500 metres, or I66 litres per kilometre.

But unless it is possible to heat the air gradually 
during its detention, and before it reaches the cylinder, unless, in fact, the heat abstracted in condensation be restored to it, the loss of power is very great. This has hitherto been the stumbling.block of compressed air engines, and M. Mékarski seems to have completely met the difficulty. He adopts as a re-heater a cylinder holding about roo litres of water, taken from the boiler of an engine, at five atmospheres, and to obtain the maximum of effect possible, the condensed air is delivered from the reservoirs to the cylinder only after traversing the entire mass of water.

By a clever contrivance $M$. Mékarski regulates at pleasure the action of the compressed air upon the piston. Two hermetically-closed boxes are placed vertically upon the re-heater; their common face is formed by a caoutchouc diaphragm, in direct connection with an obturator, which opens or shuts more or less the opening which communicates between the lower box and the chamber containing a mixture of compressed air and vapour in the upper part of the hot-water cylinder. It will be seen that this orifice will be more or less uncovered according as the pressure in the lower box will be above, or not, the pressure in the lower box. This second box is itself filled with air, and constitutes a small pump-barrel, in which a large plunger piston works. The rod of the piston is a screw, and is fitted outside with a small regulator, on which the driver works. This may rapidly be made to vary the presence of the air in the upper box, and consequently the pressure be increased or diminished of the air which is delivered from the lower box to the motory cylinder.

\section{THE GREAT TELESCOPE OF THE PARIS ORSERVATORY}

$\sqrt{\mathrm{L}} \mathrm{L}$ have from time to time noted the progress of the great telescope which for years has been in course of construction for the Paris Observatory, and now that it is completed and in its place we are glad to be able to present a view of the instrument, for which, and for the details which follow, we are indebted to $L a$ Nature.

In $1855 \mathrm{M}$. Le Verrier purchased in England two large discs, the one of flint and the other of crown glass, intended to form the material for an object-glass. The late Léon Foucault, the eminent physicist of the Observatory, was charged with the investigation of the processes which should be employed to cut these large glasses, whose dimensions were much greater than those to which opticians had been accustomed. It is known how Foucault was led, by his series of investigations, to malse mirrors of silvered glass. Successive attempts enabled him to present French observatories with reflectors of 40 , of 50 , and finally of 80 centimetres in diameter, having a tube in length only six times the diameter of the mirror. The largest of the telescopes constructed by Foucault himself, of 80 centimetres aperture, is at Marseilles, under the care of M. Stephan ; by means of it this astronomer has seen all that Herschel saw with his enormous metallic reflector of $I^{*} 45 \mathrm{~m}$. diameter, all that Lord Rosse has been able to see with his leviathan of I "7o m., and he has added hundreds of new nebulæe to the list given by his illustrious predecessors.

To crown his labours, L. Foucault wished to construct the largest mirror which it would be possible to make by his admirable method. This superior limit is $\mathrm{r} 20 \mathrm{~m}$. diameter. M. Le Verrier caused to be cast at St. Gobain a block of glass weighing 700 kilogrammes, which was rough-ground and shaped in the workshops of MM. Sauter and Lemonnier. But to construct this telescope, with its tube of 16 metres in length, required special funds, the ordinary budget of the Observatory not being sufficient. M. Le Verrier sought to obtain them from the Corps Législatif, which, in 1865 , voted a sum of 400,000 francs.

By the beginning of 1868 , Foucault, notwithstanding his researches on regulators and the fatigue caused by the active part he took in the Exposition of 1867 , had prepared the plans for the large reflector, when death snatched him from his work, and deprived France of one of the most original and finest geniuses she has possessed. This fatality, and the troubles which soon after and for long disturbed the Observatory, seemed to have lost to the country the work of years, and to have rendered useless the liberality of Government. Happily, the Minister of Public Instruction, M. Duruy, was willing to lend an attentive ear to the suggestions of men of science, and place at their service an intelligence eager for progress. At the request of the friends of Foucault he ordered the work which had been begun to be continued, and the authorities of the Observatory eagerly complied with his orders. An eminent mechanician, M. Eichens, indicated to $M$. Le Verrier by the Grand Prize in Mechanics which he obtained at the Exposition of 1867 , and by his construction of large instruments for the Observatory, received the order for the construction of the telescope. $M$. Adolphe Martin, whom Foucault had instructed in his methods and associated with himself in his optical undertakings, was charged with the polishing of the mirror. Finally, M. Le Verrier entrusted to one of the astronomers of the Observatory, M. Wolf, the general superintendence of the work.

The construction ought to have been completed in three years. The war and the changes in the Observatory caused the work to languish, and it was not resumed with vigour until the return of M. Le Verrier as Director in 1873. At the commencement of 1875 the mirror was completed and tried upon terrestrial objects; $M$. Wolf had got a shelter constructed for the telescope and the staircase for the observer; finally, in the month of October, M. Eichens sent in the instrument complete in all its main details.

The total cost of the instrument and of the observatory amounts to 190,000 francs.

The illustration which we give represents the telescope in a position for observation. The wheeled hut under which it usually stands, a sort of wagon seven metres high by nine long and five broad, is pushed back towards the north along double rails. The observing staircase has been fitted to a second system of rails, which permit it to circulate all round the foot of the telescope, at the same time that it can turn upon itself, for the purpose of placing the observer, standing either on the steps or on the upper balcony, within reach of the eye-piece. This eye-piece itself may be turned round the end of the telescope into whatever position is most easily accessible to the observer.

The tube of the telescope, 7.30 metres in length, consists of a central cylinder, to the extremities of which are fastened two tubes of 3 metres long, consisting of four rings of forged iron bound together by twelve longitudinal bars also of iron. The whole is lined with small sheets of steel plate. The total weight is about 2,400 kilogrammes. At the lower extremity is fixed the barrel which holds the mirror; at the other end a circle, movable on the open mouth of the telescope, carries at its centre a plane mirror, which throws to the side the cone of rays reflected by the great mirror. The telescope is thus on the Newtonian system. That of Melbourne, so admirably constructed in England, is a Cassegrain telescope; the metallic mirror is pierced at its centre by an aperture which receives the eye-piece, a system so far advantageous that the observer always remains at the lower part of his instrument, and has to raise himself only a very short distance above ground, but less calculated perhaps to produce a perfect image than the Newtonian system adopted by Foucault.

The weight of the mirror in its barrel is about 800 kilogrammes; the eye-piece and its accessories have the same weight. Such is the load under which the tube of 